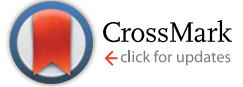

Cite this: Chem. Sci., 2016, 7, 2870

\section{Extremely condensing triplet states of DPEPO-type hosts through constitutional isomerization for high-efficiency deep-blue thermally activated delayed fluorescence diodes $\uparrow$}

\begin{abstract}
Jing Zhang, Dongxue Ding, Ying Wei* and Hui Xu*
The similarity of thermally activated delayed fluorescence (TADF) dyes and their hosts as pure organic molecules makes hosts predominant in intermolecular interactions and crucial to exciton harvesting and utilization in TADF diodes. DPEPO is the most popular high-energy-gap blue TADF host with steric ortho-substituted diphenylphosphine oxide (DPPO) groups for intermolecular interaction suppression, but suffers from serious efficiency roll-off due to its weak electroactivity. On the contrary, parasubstituted DPPO with small steric hindrance is superior in intramolecular electronic coupling. In this work, four constitutional isomers of DPEPO are constructed as diphenylether (DPE) with two diphenylphosphine oxide (DPPO) groups substituted at either the 2 or 4 position, namely 22'DPEPO (viz. DPEPO), 24DPEPO, 24'DPEPO and 44'DPEPO, respectively. On the basis of separation configuration, the steric effect and electroactivity of ortho- and para-substituted DPPOs are successfully integrated in 24'DPEPO, accompanied by remarkably reduced intermolecular interactions due to its unsymmetrical configuration. Compared to its congeners, $24^{\prime}$ DPEPO has a rigid structure and locally excited states similar to $22^{\prime}$ DPEPO for interaction suppression and improved charge mobility comparable to $44^{\prime}$ DPEPO for charge flux balance. Significantly, by virtue of the predominant orientation effect of ortho-DPPO on the $T_{1}$ location, its $T_{1}$ state is extremely condensed onto a single phenyl, protected from intermolecular interactions by its remaining five phenyls at its maximum extent. Consequently, 24'DPEPO endowed its DMAC-DPS-based deep-blue devices with state-of-the-art performance, including high color purity with chromaticity coordinates of $(0.16,0.17)$, external quantum efficiency (EQE) beyond $20 \%$ and EQE roll-off as low as $32 \%$ at $1000 \mathrm{~cd} \mathrm{~m}^{-2}$. It is shown that the device performance of $24^{\prime}$ DPEPO was far beyond simple integration of those of $22^{\prime}$ DPEPO and $44^{\prime}$ DPEPO, verifying the significance of host optimization.
\end{abstract}

Received 15th December 2015 Accepted 7th January 2016

DOI: $10.1039 / \mathrm{c} 5 \mathrm{sc} 04848 f$

www.rsc.org/chemicalscience excitons in the electroluminescence process and the strong intermolecular interactions of TADF dyes, host materials are commonly adopted to dilute emitters and restrain exciton quenching in TADF diodes. ${ }^{6}$ However, in contrast to their phosphorescent counterparts, as the same pure organic materials, TADF dyes show molecular components and excited characteristics similar to their hosts, especially their comparable triplet lifetimes. It is rational that as it forms the majority of emissive layers (EML), the host is dominant in intermolecular interplay, including host-host and host-dopant interactions. ${ }^{8}$ In this case, besides the basic functions for host materials, viz. carrier flux balance and energy transfer, their structures and optoelectronic properties would exert great influence on collision-induced exciton quenching effects, such as triplettriplet annihilation (TTA, Fig. 1a) and triplet-polaron quenching (TPQ, Fig. 1b). ${ }^{9}$ Therefore, compared to phosphorescent OLEDs, host materials in TADF diodes play a more vital role in exciton harvesting and utilization., ${ }^{\mathbf{8} 10}$
Key Laboratory of Functional Inorganic Material Chemistry, Ministry of Education \& School of Chemistry and Material Science, Heilongjiang University, 74 Xuefu Road, Harbin 150080, P. R. China.E-mail: hxu@hlju.edu.cn; ywei@hlju.edu.cn

$\dagger$ Electronic supplementary information (ESI) available. See DOI: 10.1039/c5sc04848f 


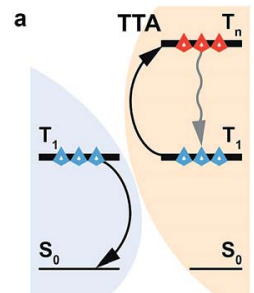

Exciton1 Exciton2

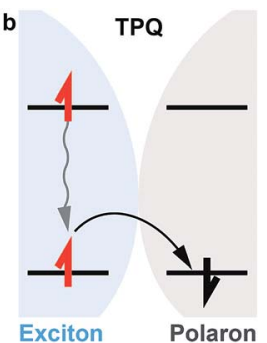

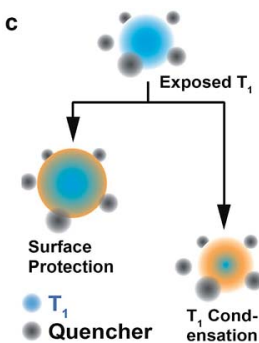

d

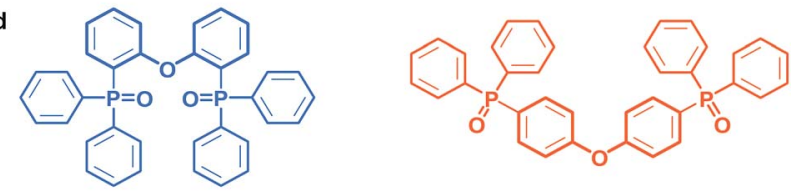

Fig. 1 Mechanisms of triplet-triplet annihilation (TTA, a) and tripletpolaron quenching (TPQ, b), two $T_{1}$ state protection strategies through surface modification and location condensation (c) and molecular design of DPEPO-type constitutional isomers mDPEPO (d).

The collision between two triplet excitons can render TTA. ${ }^{11}$ That is, one exciton is annihilated through transferring its energy to the other, making the latter excited to a higher level and then recovering to the first triplet $\left(\mathrm{T}_{1}\right)$ state through internal conversion (IC) (Fig. 1a). Meanwhile, TPQ occurs during collision between an exciton and polaron, which induces the nonradiative deactivation of the former through charge exchange (Fig. 1b). ${ }^{12}$ In consequence, three approaches would be effective for quenching suppression: (i) embedding and/or segregating $\mathrm{T}_{1}$-localized moieties of host and dopant molecules to protect triplet excitons from collision quenching with surrounding modification ${ }^{13}$ and $T_{1}$ state condensation, ${ }^{\mathbf{1 4}}$ in spite of only a few reports about $\mathrm{T}_{1}$ condensation (Fig. 1c); (ii) reducing collision probability through shortening exciton lifetime; (iii) enhancing charge flux balance and unifying exciton recombination to decrease polaron concentration. In this case, the excited-state characteristics and carrier-transporting ability of host materials should be a determinant for their electroluminescence (EL) efficiencies.

It is known that the CT-type exciton is labile and highly sensitive to the environment. ${ }^{15}$ Consequently, although $100 \%$ internal quantum efficiencies were already achieved for TADF devices, most of them suffered from serious efficiency roll-off, especially for blue TADF diodes utilizing high-energy excitons. DPEPO is the most popular host for blue TADF diodes. ${ }^{4 a, 5 e, 5 i, 5 j, 16}$
Its multi-insulating structure and the steric effect of $\mathrm{P}=\mathrm{O}$ groups give rise to its high $\mathrm{T}_{1}$ value of $\sim 3.0 \mathrm{eV}$ for efficient energy transfer to blue TADF dyes, e.g. bis[4-(9,9-dimethyl-9,10dihydroacridine)phenyl]sulfone (DMAC-DPS) $\left(\mathrm{T}_{1}=2.90 \mathrm{eV}\right)^{\mathbf{1 6 a}}$ and quenching suppression. ${ }^{17}$ The external quantum efficiency (EQE) of deep-blue TADF devices with DMAC-DPS as the emitter reached $\sim 20 \%$, however, this was accompanied by remarkable roll-off of more than $90 \%$ at $1000 \mathrm{~cd} \mathrm{~m}^{-2}$, indicating serious exciton quenching. ${ }^{18}$ Nevertheless, how to optimize optoelectronic properties of blue TADF host materials is really challenging, since many key issues are still unclear, especially the influences and correlations of their electrical properties and excited-state characteristics and their merits. ${ }^{19}$ In our previous work, it was shown that these two factors strongly depend on the functional linkage site and molecular sequence. ${ }^{20}$ In this sense, the isomerization of DPEPO may provide a feasible way to clarify the key determinants of EL performance for deep blue TADF host materials.

In this contribution, four constitutional isomers of DPEPO with the collective name of $\boldsymbol{m D P E P O}$ are constructed as bis(diphenylphosphoryl) diphenylether with two diphenylphosphine oxide (DPPO) groups at either the 2 or 4 position of their diphenylether (DPE) cores, named 22'DPEPO (viz. DPEPO), 24DPEPO, 24' DPEPO and $\mathbf{4 4}^{\prime}$ DPEPO, respectively (Fig. 1d). DPPO at the 2-position indicates the strong steric effect and dominant localization effect on the $\mathrm{T}_{1}$ state, while DPPO at the 4-position is superior in enhancing intramolecular electronic coupling. By virtue of the asymmetrical and separated structure for $\mathbf{2 4}^{\prime}$ DPEPO, the functions of its two kinds of DPPO groups are successfully integrated. Significantly, its $T_{1}$ state is extremely condensed to a single phenyl, embedded and protected by its remaining five phenyls at its maximum extent. Meanwhile, compared to $22^{\prime} \mathbf{D P E P O}$, the electron mobility of $24^{\prime} \mathbf{D P E P O}$ is dramatically improved by about 50 times. Consequently, its DMAC-DPS-based deep-blue devices realized state-of-the-art performance, including high color purity with CIE coordinates of $(0.16,0.17)$, an EQE beyond $20 \%$ and EQE roll-off as low as $32 \%$ at $1000 \mathrm{~cd} \mathrm{~m}^{-2}$. The efficiencies of $\mathbf{2 4}^{\prime}$ DPEPO-based devices were improved by $20 \%$ in comparison to those employing 22'DPEPO as the host; meanwhile, the roll-offs of the former were halved. It is clear that host engineering is a gateway to resolving the key issues of TADF devices in exciton harvesting and utilization.

\section{Results and discussions}

\subsection{Design and synthesis}

DPPO is an electron-withdrawing group with big steric hindrance. Its dominant function depends on its substitution positions. For instance, DPPOs at ortho-positions of $22^{\prime}$ DPEPO are superior in their steric effect; while, DPPOs in $\mathbf{4 4}^{\prime}$ DPEPO can enhance intramolecular coupling with an electron-donating ether bridge at the para-position (Fig. 1c). In this case, an intermolecular interaction with $22^{\prime}$ DPEPO at the DPPOsubstituted side can be thoroughly blocked to effectively suppress TTA. However, electronic coupling in $22^{\prime}$ DPEPO is remarkably weaker due to its ortho-substitution configuration. ${ }^{17}$ 
In contrast, sufficient electronic coupling in $\mathbf{4 4}^{\prime}$ DPEPO can support balanced hole and electron flux in its EMLs, facilitating exciton recombination and reducing TPQ. ${ }^{21}$ Nonetheless, its DPE chromophore is completely exposed to intermolecular interactions, worsening TTA. Therefore, it is well-reasoned to combine these two kinds of DPPO substitutions in one single molecule for integrating their advantages and thereby simultaneously suppressing TTA and TPQ.

More significantly, in our recent works, it was shown that DPPO substitution can regulate $\mathrm{T}_{1}$ location, which should be attributed to the influence of the $\mathrm{P}=\mathrm{O}$ group on electron cloud distribution. ${ }^{\mathbf{1 4 , 2 0 a , 2 2}}$ In this sense, the orientation effect of DPPO on the $T_{1}$ state would be related to its substitution position. Therefore, with asymmetrical DPPO substitutions, the $\mathrm{T}_{1}$ states of the molecules can be condensed into a designated location by DPPO with a dominant orientation effect. The narrow $T_{1}$ location can amplify the protective action of surrounding groups and further reduce its probability of involvement in intermolecular interactions. Regarding DPEPO-type analogues, since all of their phenyls are separated by insulating linkages, it can be expected to confine their $\mathrm{T}_{1}$ states into a single phenyl, which is almost the minimum for conjugated compounds with respect to spatial scale.

With these considerations, two other asymmetrical isomers, namely 24DPEPO and $\mathbf{2 4}^{\prime}$ DPEPO, incorporating both ortho- and para-linked DPPO groups were designed. Two DPPOs in 24DPEPO are bonded with the same phenyl, while those in $\mathbf{2 4}^{\prime}$ DPEPO are respectively bonded with two different phenyls of DPE. The superposition of two DPPOs in 24DPEPO may render the mutual acceleration or counteraction of their effects. On the contrary, by virtue of the insulating ether bridge, the two separated DPPOs of $24^{\prime}$ DPEPO can perform their functions independently. In consequence, it is most likely for $\mathbf{2 4}^{\prime} \mathbf{D P E P O}$ to integrate the merits of $22^{\prime}$ DPEPO and $\mathbf{4 4}^{\prime}$ DPEPO. Simultaneously, the multi-insulating linkage establishes the similarity of $\boldsymbol{m D P E P O}$ to the maximum extent, excluding the interference from undesirable intramolecular interplay and conjugation variation, which simplifies the influencing factors of their device performance into electrical and excited-state characteristics.

mDPEPO can be conveniently prepared through Pd-catalyzed phosphorylation with good yields of more than 50\%. Their chemical structures were fully characterized on the basis of NMR spectra, mass spectra and elementary analysis. Among $\boldsymbol{m D P E P O}$, the biggest steric hindrance in 22'DPEPO increases its intramolecular tension, rendering its lowest temperature of decomposition $\left(T_{\mathrm{d}}\right)$ as $322{ }^{\circ} \mathrm{C}$; while its rigid and monosymmetrical structure results in its highest melting point $\left(T_{\mathrm{m}}\right)$ of $280{ }^{\circ} \mathrm{C}$ (Fig. S1† and Table 1). On the contrary, owing to negligible steric hindrance in $\mathbf{4 4}^{\prime} \mathbf{D P E P O}$, its $T_{\mathrm{d}}$ is remarkably improved to $417^{\circ} \mathrm{C}$, however, this is accompanied by a reduced $T_{\mathrm{m}}$ of $190{ }^{\circ} \mathrm{C}$. The rotatable phenyl of DPE in 24DPEPO makes its thermal properties similar to those of $\mathbf{4 4}^{\prime}$ DPEPO. Importantly, $\mathbf{2 4}^{\prime}$ DPEPO shows a $T_{\mathrm{d}}$ equivalent to that of $\mathbf{4 4}^{\prime} \mathbf{D E P P O}$ and a $T_{\mathrm{m}}$ comparable to that of $22^{\prime} \mathbf{D P E P O}$. Therefore, one orthosubstituted DPPO in $\mathbf{2 4}^{\prime}$ DPEPO already revealed sufficiently strong molecular rigidity.

\subsection{DFT and TDDFT simulation}

For insight into the nature of the effects of DPPO substitution on electrical and excited-state characteristics of $\boldsymbol{m D P E P O}$, DFT and TDDFT calculations were performed at the level of B3LYP/6$31+\mathrm{g}(\mathrm{d}, \mathrm{p})$, taking into account computational accuracy and cost.

The optimized molecular configurations of $\mathbf{m D P E P O}$ at ground $\left(\mathrm{S}_{0}\right)$, the first singlet $\left(\mathrm{S}_{1}\right)$ and $\mathrm{T}_{1}$ states are shown in Fig. 2. Ascribed to the biggest steric hindrance of its two orthosubstituted DPPOs, the dihedral angle of DPE in 22'DPEPO at the $\mathrm{S}_{0}$ state is the largest among $\mathbf{m D P E P O}$, which is almost preserved at its $S_{1}$ and $T_{1}$ states. The dihedral angles of DPE in 44'DPEPO at these states are the smallest, in accord with the smaller steric hindrance of its DPPOs at the para-position. Compared to the ground state, its excited-state configurations are adjusted. Nevertheless, 24DPEPO shows the largest configuration variation at excited states, which is ascribed to the rotational phenyl of its DPE. In this sense, both ortho- and paraDPPO substitution can reduce excited-state structural relaxation. Consequently, the molecular configurations of $24^{\prime}$ DPEPO at $\mathrm{S}_{0}, \mathrm{~S}_{1}$ and $\mathrm{T}_{1}$ states are almost unchanged, accompanied by the dihedral angles of DPE close to those of $22^{\prime}$ DPEPO. In comparison to 24DPEPO, the fixed molecular configurations of $24^{\prime}$ DPEPO and $22^{\prime}$ DPEPO make them superior in reducing relaxation-induced excited-energy loss, which is beneficial to improving luminescent efficiency.

The contours of the highest occupied and the lowest unoccupied molecular orbitals (HOMO and LUMO) for mDPEPO reveal the influence of DPPO substitution position on hole and electron injecting ability, respectively. Although the frontier molecular orbitals (FMO) of $22^{\prime}$ DPEPO are respectively localized on its DPE and DPPO groups, its LUMO energy level is the highest among $\boldsymbol{m D P E P O}$, indicating the weakest electronwithdrawing ability of its DPPOs at the 2-position (Fig. 2, S2 $\uparrow$ and Table 1). The situations of $\mathbf{4 4}^{\prime}$ DPEPO and 24DPEPO are similar, with partially separated HOMO and LUMO. However, the superposition of DPPOs in 24DPEPO renders the simultaneously reduced HOMO and LUMO energy levels. In contrast, 44'DPEPO possesses a HOMO and LUMO that are almost equivalent to those of $22^{\prime}$ DPEPO and 24DPEPO, respectively, causing the enhanced intramolecular electronic coupling in 44'DPEPO and its ambipolar characteristics. As expected, through incorporating the para-substituted DPPO, in comparison to $22^{\prime}$ DPEPO, the HOMO energy level of $24^{\prime}$ DPEPO is preserved, while its LUMO energy level is reduced by $0.12 \mathrm{eV}$, which is similar to that of $\mathbf{4 4}^{\prime} \mathbf{D P E P O}$. Therefore, it is shown that despite its overlapping HOMO and LUMO distributions, the charge injecting ability of $\mathbf{2 4}^{\prime} \mathbf{D P E P O}$ is mainly determined by its para-linked DPE-DPPO segment.

The calculated $S_{1}$ and $T_{1}$ energies of $\boldsymbol{m D P E P O}$ are almost the same as $\sim 4.7$ and $\sim 3.5 \mathrm{eV}$, supporting positive energy transfer to DMAC-DPS with the $S_{1}$ and $T_{1}$ value of $\sim 2.9 \mathrm{eV}$ (Fig. 2 and Table 1). The similar excited energy of $\mathbf{m D P E P O}$ is attributed to their multi-insulating structures. It is rational that on the basis of monosymmetric configurations and two equivalent DPPOs, the $\mathrm{T}_{1}$ states of $22^{\prime} \mathrm{DPEPO}$ and $\mathbf{4 4}^{\prime} \mathrm{DPEPO}$ are uniformly dispersed on their DPE groups. In accord with our previous 
Table 1 Physical properties of $m$ DPEPO

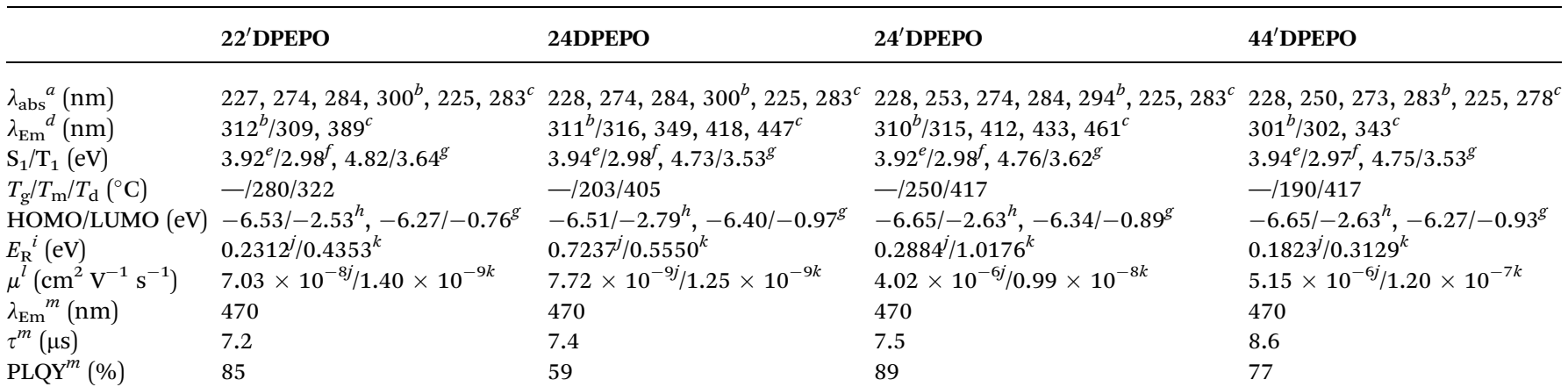

${ }^{a}$ Absorption peaks. ${ }^{b}$ In $\mathrm{CH}_{2} \mathrm{Cl}_{2}\left(10^{-6} \mathrm{~mol} \mathrm{~L}^{-1}\right) \cdot{ }^{c}$ In polycrystalline powder. ${ }^{d}$ Fluorescence peaks at room temperature. ${ }^{e}$ Estimated according to the absorption edges. ${ }^{f}$ Calculated according to the $0-0$ transitions of the phosphorescence spectra. ${ }^{g}$ TDDFT calculated results. $^{h}$ Calculated according to the equation $\mathrm{HOMO} / \mathrm{LUMO}=-(4.78+$ onset voltage $) \mathrm{eV} \cdot{ }^{1}{ }^{i}$ Reorganization energy of electron. ${ }^{j}$ For electron. ${ }^{k}$ For hole. ${ }^{l}$ Electron mobility estimated by $I-V$ characteristics of electron-only devices according to field-dependent SCLC model. ${ }^{m}$ Data of vacuum-evaporated mDPEPO:DMAC-DPS (10\% wt) films with thickness of $100 \mathrm{~nm}$.

reports, DPPO substitution has an effect on $\mathrm{T}_{1}$ location regulation. ${ }^{20 a}$ The $T_{1}$ state of 24DPEPO is mainly contributed by the phenyl substituted with two $\mathrm{P}=\mathrm{O}$ groups. Interestingly, 24'DPEPO shows a $\mathrm{T}_{1}$ state that is thoroughly localized on the 2-DPPO substituted phenyl, reflecting the dominant orientation effect of ortho-substituted DPPO on the $\mathrm{T}_{1}$ state. The $\mathrm{T}_{1}$ state of $\mathbf{2 4}^{\prime}$ DPEPO is extremely condensed on a single phenyl as one of the smallest conjugated units, which is embedded by its remaining five phenyls. Compared to its isomers, the exposure degree of the $\mathrm{T}_{1}$ state of $\mathbf{2 4}^{\prime} \mathbf{D P E P O}$ is doubtlessly the smallest, which can support the most effective suppression of collisioninduced quenching effects.

The nature of electronic transitions for the excited states of mDPEPO was further evaluated with natural transition orbitals (NTO) of the first singlet and triplet excitations (Fig. 3 and $\mathrm{S} 4 \dagger) .{ }^{23}$ In the cases of NTOs about $\mathrm{S}_{0} \rightarrow \mathrm{S}_{1}$ states for mDPEPO, "holes" are thoroughly localized on their DPE. However, the distributions of "particles" are various, such that for 22' DPEPO and 24'DPEPO, "particles" are also dispersed on their DPE, featuring locally excited (LE) state transition; while, for 24DPEPO, "holes" are concentrated to one phenyl of DPE, and for $\mathbf{4 4}^{\prime}$ DPEPO, "holes" are partially dispersed on DPPO groups, characteristic of hybridized local and charge transfer excited states. Nevertheless, the biggest oscillator strength $(f)$ suggests the LE transition of DPE as the major part for $\mathbf{4 4}^{\prime} \mathbf{D P E P O}$, while CT transition between two phenyls of DPE is dominant for 24DPEPO with the smallest $f$. NTOs of $\mathrm{S}_{0} \rightarrow \mathrm{T}_{1}$ states for $\boldsymbol{m D P E P O}$ reveal an LE character with overlapped "hole" and "particle" locations. In accord with the DFT results, triplet states of $2^{\prime}$ DPEPO and $4^{\prime}$ DPEPO are dispersed on their DPE, while only a single phenyl of 24DPEPO and $24^{\prime}$ DPEPO is involved in their triplet transitions. Regarding CT character of excitons on TADF dyes, LE-dominant excited states of hosts can provide uniform and apparently neutral matrices to restrain Coulomb interaction induced CT exciton dissociation.

It is shown that $\mathbf{2 4}^{\prime}$ DPEPO successfully integrates the merits of ortho- and para-DPPO substitutions, including excited structural stability, singlet characteristics comparable to $\mathbf{2 2}^{\prime}$ DPEPO and FMO energy levels close to $\mathbf{4 4}^{\prime}$ DPEPO. In addition to significantly reinforced $T_{1}$ state protection through an extremely condensed $\mathrm{T}_{1}$ location on the minimum unit phenyl, 24'DPEPO shows superiority in quenching suppression and charge balance. In contrast, 24DPEPO exhibits some shortages of serious excited structural relaxation and a CT-dominant $\mathrm{S}_{1}$ characteristic.

\subsection{Optical properties}

The absorption spectra of $\boldsymbol{m D P E P O}$ in dilute solutions $\left(10^{-6} \mathrm{M}\right.$ in $\mathrm{CH}_{2} \mathrm{Cl}_{2}$ ) consist of three bands at around 230, 270 and $300 \mathrm{~nm}$, corresponding to $\pi \rightarrow \pi^{*}$ transitions of DPPO and DPE and the $\mathrm{n} \rightarrow \pi^{*}$ transition of DPE, respectively (Fig. 4a). The spectra of 22'DPEPO, 24DPEPO and 24'DPEPO are almost identical, but different to that of $\mathbf{4 4}^{\prime} \mathbf{D P E P O}$. As indicated by the DFT results, the smallest dihedral angle of DPE in $44^{\prime}$ DPEPO facilitates $\pi-\pi$ interactions between the two phenyls of DPE and decreases $\mathrm{p}-\pi$ conjugation between the $\mathrm{O}$ atom and phenyls, accordingly enhancing $\pi \rightarrow \pi^{*}$ transition and weakening $\mathrm{n} \rightarrow \pi^{*}$ transition. Nevertheless, the optical energy gaps of $\boldsymbol{m D P E P O}$ estimated by absorption edges are almost identical to $3.9 \mathrm{eV}$, consistent with TDDFT results (Table 1).

In the same way, the fluorescence (FL) spectra of $2^{\prime}$ DPEPO, 24DPEPO and 24'DPEPO in dilute solutions $\left(10^{-6} \mathrm{M}\right.$ in $\left.\mathrm{CH}_{2} \mathrm{Cl}_{2}\right)$ are exactly the same in range and profile. Meanwhile, the FL spectrum of $\mathbf{4 4}^{\prime}$ DPEPO reveals a blue shift of $\sim 10 \mathrm{~nm}$. Nonetheless, there are large-range spectral overlaps between $\mathrm{FL}$ emissions of $\boldsymbol{m D P E P O}$ and absorption of DMAC-DPS from 275 to $350 \mathrm{~nm}$, facilitating Förster resonance energy transfer (FRET). The low-temperature time-resolved phosphorescence (PH) spectra of $\boldsymbol{m D P E P O}$ are identical, with the same peaks and profiles, which is in accord with their similar $\mathrm{T}_{1}$ transition characteristics as shown by TDDFT simulation (inset of Fig. 4a). Estimated with $0 \rightarrow 0$ transitions, the $\mathrm{T}_{1}$ value of $\boldsymbol{m D P E P O}$ is equivalent to $2.98 \mathrm{eV}$, supporting the efficient triplet energy transfer to DMAC-DPS. The similar excited energy of these DPEPO-type isomers fully verifies the effectiveness of multiinsulating linkages in excited energy preservation. 

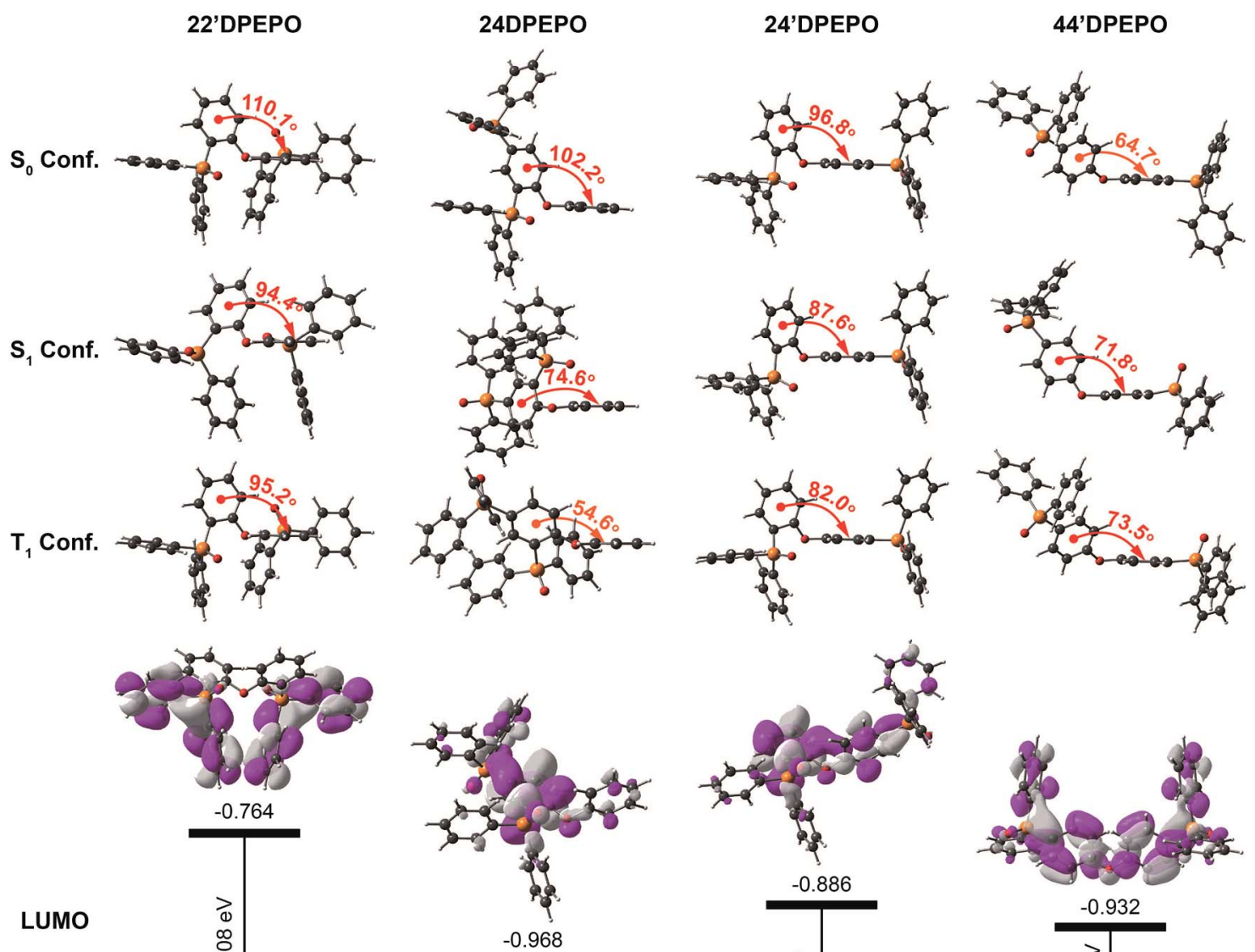

LUMO
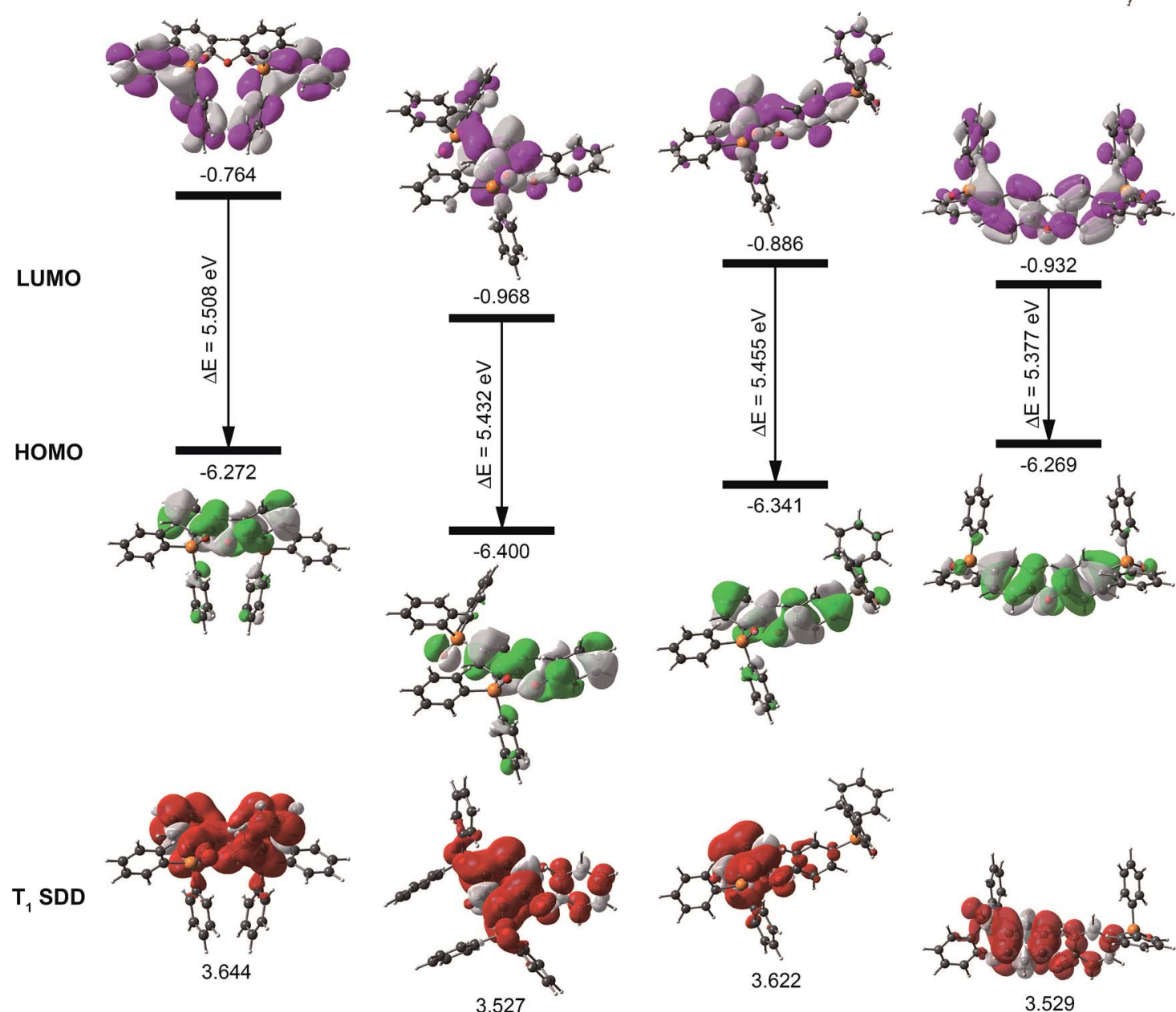

Fig. 2 DFT and TDDFT simulations of ground, $\mathrm{S}_{1}$ and $\mathrm{T}_{1}$ excited states for $m$ DPEPO: configurations, the LUMO and HOMO orbital distributions of ground states and the spin density distributions of $T_{1}$ states.

The optical properties of $\boldsymbol{m D P E P O}$ in the solid state were further investigated to exclude solvent effects (Fig. 4b). The main absorption bands are preserved in the solid-state spectra, reflecting the limited intermolecular interactions. However, in contrast to the unchanged fluorescence emission of 22'DPEPO in the solid state, $\mathbf{4 4}^{\prime}$ DPEPO shows an additional broad aggregation-induced emission band in the long-wavelength range from 325 to $450 \mathrm{~nm}$, in accord with the weak steric effect 


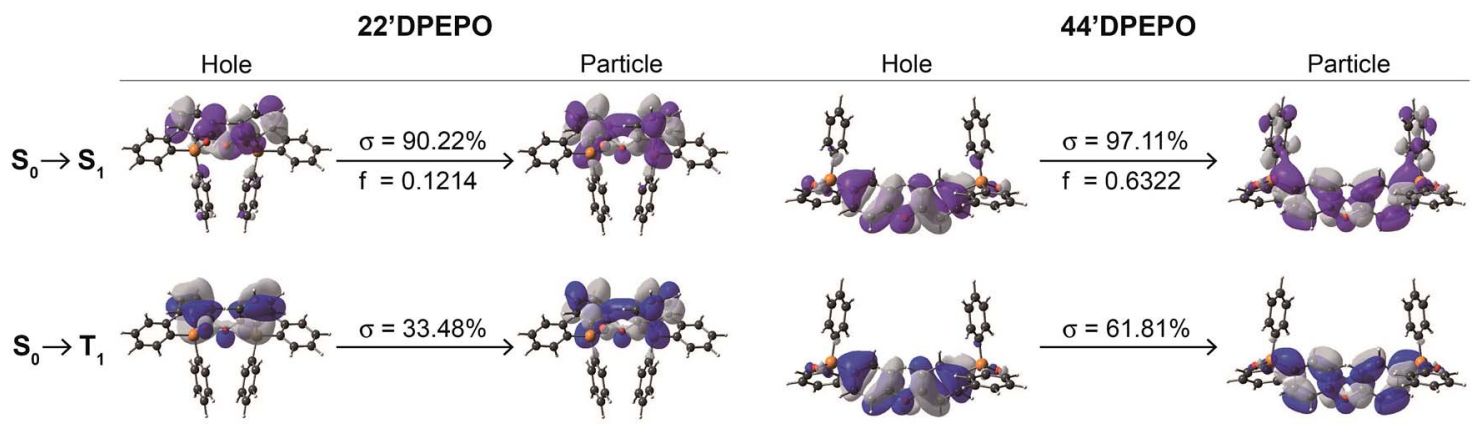

24DPEPO

24'DPEPO

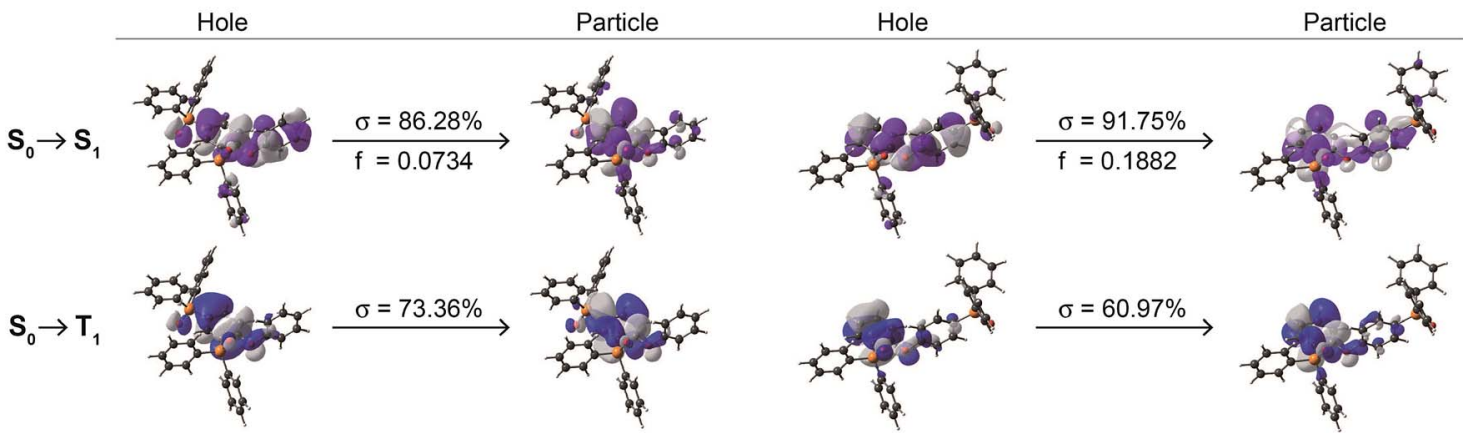

Fig. 3 Natural transition orbitals (NTO) of the $S_{1}$ and $T_{1}$ states for $m$ DPEPO. $\sigma$ and $f$ refer to the associated weight and oscillator strength, respectively.

of its para-DPPOs. The flexible DPE in 24DPEPO also facilitates aggregation, rendering a similar broad band at around $340 \mathrm{~nm}$. As expected, by virtue of the strong steric effect of orthosubstituted DPPO in $\mathbf{2 4}^{\prime}$ DPEPO with a separation configuration, the aggregation in the solid state is successfully suppressed, making one of its solid-state emission bands at $315 \mathrm{~nm}$ almost overlapped with its emission in solution. Significantly, solid-state emissions of $24^{\prime}$ DPEPO and 24DPEPO contain additional distinct multi-peak bands coincident with the blue parts of their phosphorescence, whose lifetimes $(\tau)$ are also comparable to $\sim 7 \mu$ s (Fig. S3 $\dagger$ ); meanwhile, for $22^{\prime}$ DPEPO and $\mathbf{4 4}^{\prime}$ DPEPO, their solid-state phosphorescence is fully quenched through nonradiative transitions due to their exposed $\mathrm{T}_{1}$ states. In dilute solutions, the small volumes of solvent molecules make collision with every part of solute molecules facile, resulting in serious solvent quenching effects on $\mathrm{T}_{1}$ states, which can be excluded in the solid state. Recently, room-temperature phosphorescence from crystalline pure organic molecules was realized on the basis of D-A systems with overlapping $S_{1}$ and $T_{1}$ locations. ${ }^{24}$ It is rational to attribute the visible room-temperature solid-state phosphorescence of $\mathbf{2 4}^{\prime}$ DPEPO and 24DPEPO to their extremely condensed $\mathrm{T}_{1}$ state, effectively protected from interactioninduced triplet quenching, which validates $T_{1}$ condensation as a feasible and effective strategy to achieving and enhancing room-temperature phosphorescence from pure organic systems.

The host-dopant energy transfer was further investigated through steady-state and transient photoluminescence (PL) spectra of vacuum-evaporated DMAC-DPS-doped $\boldsymbol{m D P E P O}$ films
(Fig. 4c). The emission spectra are almost identical, with the maxima at $470 \mathrm{~nm}$, corresponding to the pure DMAC-DPSoriginated emission, which indicates the same positive energy transfer from $\boldsymbol{m D P E P O}$ consistent with their equivalent $\mathrm{S}_{1}$ and $\mathrm{T}_{1}$ energy. As mentioned above, the $\tau$ of $\mathrm{T}_{1}$ states for $\boldsymbol{m D P E P O}$ and emissions of their DMAC-DPS-doped films is of the same order of magnitude, making $\mathbf{m D P E P O}$-involved interactions dominant in triplet quenching processes. The $\tau$ of the $\mathbf{4 4}^{\prime}$ DPEPO-based film is $8.6 \mu \mathrm{s}$, about $1 \mu$ s longer than those of the other isomer based films, revealing the effect of $\mathbf{4 4}^{\prime}$ DPEPO with a partial CT-featured $S_{1}$ state on stabilizing DMAC-DPS excitons. ${ }^{8}$ In spite of the CT-dominant $\mathrm{S}_{1}$ state, the $\tau$ of the 24DPEPO-based film is much shorter due to its structural relaxation-induced exciton quenching, which is further manifested by its lowest PL quantum yield (PLQY) of only 59\% (Table 1). Furthermore, it is known that a longer lifetime would worsen collision-induced exciton quenching. Therefore, in comparison to the PLQY of $\mathbf{7 7 \%}$ for the $\mathbf{4 4}^{\prime} \mathbf{D P E P O}$-based film, 22'DPEPO and 24'DPEPO endow their films with PLQYs as high as 85 and $89 \%$, respectively.

In consequence, the optical properties of $24^{\prime}$ DPEPO and 22'DPEPO are identical, originating from their similar excitedstate characteristics as TDDFT simulated.

\subsection{Electrical properties}

The influence of DPPO substitution position on the HOMO and LUMO energy levels is experimentally investigated with cyclic voltammetry (CV) analysis (Fig. 5a). The oxidation voltammograms of $\boldsymbol{m D P E P O}$ consist of two irreversible peaks 
a

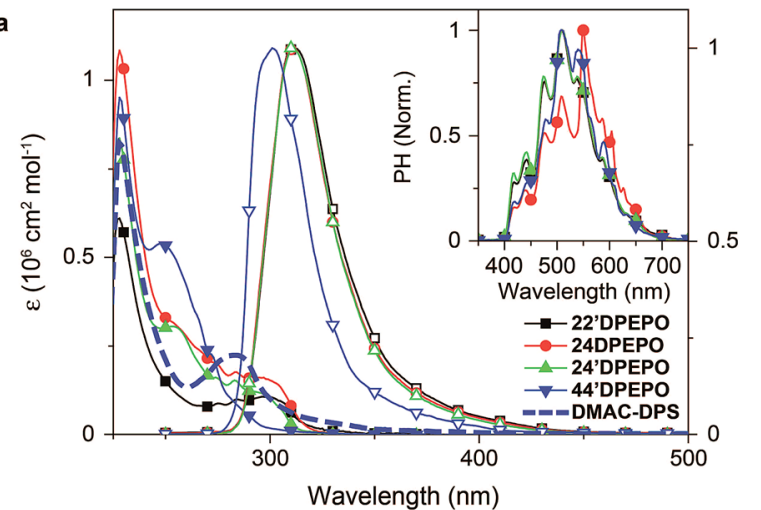

b

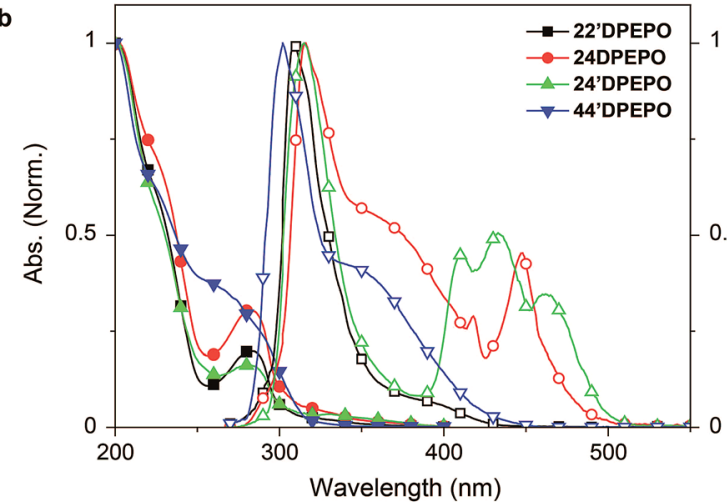

c

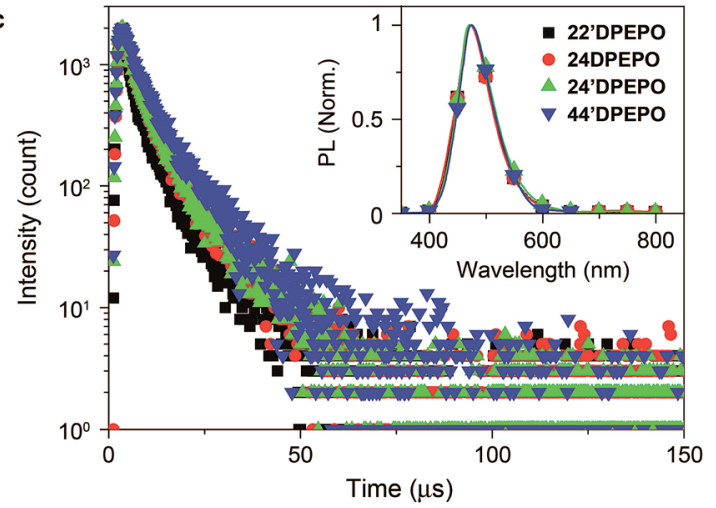

Fig. 4 (a) Electronic absorption spectra, room-temperature emission spectra of $m D P E P O$ in $\mathrm{CH}_{2} \mathrm{Cl}_{2}\left(10^{-6} \mathrm{M}\right)$. Inset shows the time-resolved phosphorescence spectra of $m$ DPEPO in $\mathrm{CH}_{2} \mathrm{Cl}_{2}$ glass at $77 \mathrm{~K}$ after a delay of $100 \mu \mathrm{s}$; (b) absorption and fluorescence (FL) spectra of polycrystalline powder for mDPEPO; (c) time decay curves and emission spectra (inset) of DMAC-DPS-doped mDPEPO films $(10 \%$, $100 \mathrm{~nm}$ ) through vacuum-evaporation.

characteristic of DPE and DPPO, respectively. Estimated with onset voltages of the anodic peaks, the HOMO energy level of 24'DPEPO is equivalent to that of $\mathbf{4 4}^{\prime} \mathrm{DPEPO}$ at $-6.65 \mathrm{eV}$, which is $0.1 \mathrm{eV}$ lower than those of 22'DPEPO and 24DPEPO (Table 1). On the other hand, the reduction voltammograms of 22'DPEPO, $\mathbf{2 4}^{\prime}$ DPEPO and 44'DPEPO only contain single irreversible cathodic peaks, while 24' DPEPO shows two irreversible reduction peaks attributed to DPE and DPPO, respectively. It is shown that the reduction curves of $24^{\prime}$ DPEPO and $\mathbf{4 4}^{\prime}$ DPEPO are almost overlapped with the same onset voltages of $-2.15 \mathrm{~V}$,
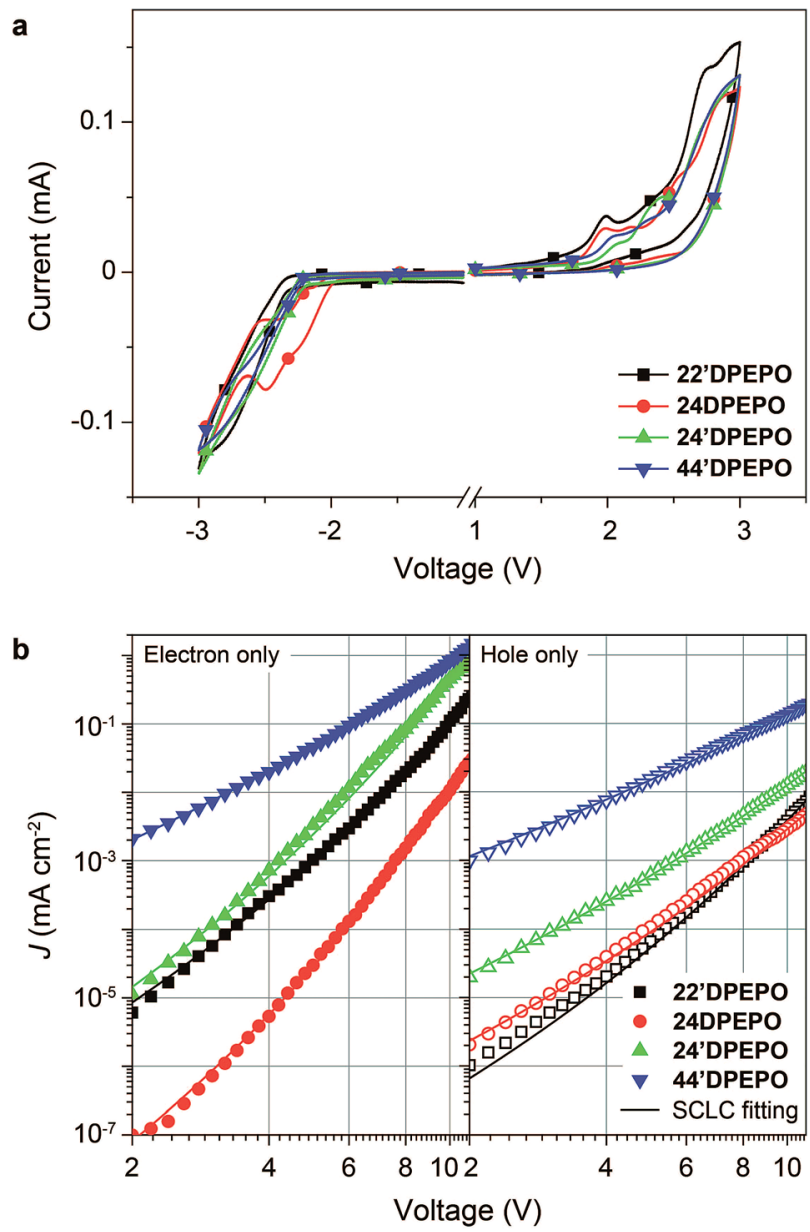

Fig. 5 (a) Cyclic voltammograms of $m$ DPEPO measured in tetrahydrofuran for reduction and dichloromethane for oxidation, respectively, at room temperature with tetrabutylammonium hexafluorophosphate as the electrolyte under a scanning rate of $100 \mathrm{mV} \mathrm{s}^{-1}$; (b) volt-ampere characteristics of single-carrier only transporting devices based on $m$ DPEPO and the corresponding fitting curves according to field-dependent SCLC model.

corresponding to the LUMO of $-2.63 \mathrm{eV}$. The superposition of two DPPOs in 24DPEPO further reduces its LUMO to $-2.79 \mathrm{eV}$, which is in accord with the DFT results. It is clear that in comparison to $22^{\prime} \mathbf{D P E P O}$, the stronger electron-withdrawing effect of para-DPPO substitution endows 24'DPEPO and 44'DPEPO with the deeper LUMOs. Significantly, the identical FMO energy levels of $\mathbf{2 4}^{\prime}$ DPEPO and $\mathbf{4 4}^{\prime}$ DPEPO verify the dominant effect of para-DPPO in FMO energy level regulation.

The nominal single-carrier transporting devices with singlelayer configurations of ITO $\left|\mathrm{MoO}_{3}(6 \mathrm{~nm})\right| \boldsymbol{m D P E P O}(100 \mathrm{~nm}) \mid$ $\mathrm{MoO}_{3}(6 \mathrm{~nm}) \mid \mathrm{Al}$ for hole only and ITO $|\operatorname{LiF}(1 \mathrm{~nm})| \boldsymbol{m D P E P O}(100$ $\mathrm{nm})|\mathrm{LiF}(1 \mathrm{~nm})| \mathrm{Al}$ for electron only, where $\mathrm{MoO}_{3}$ and $\mathrm{LiF}$ respectively served as hole- and electron-injecting layers, were fabricated to evaluate the intrinsic carrier transporting ability of $m$ DPEPO (Fig. 5b). All of these materials show electron predominant characteristics with electron-only current density $(J)$ remarkably larger than hole-only $J$. According to fielddependent space charge limited current model, the hole 
mobility $\left(\mu_{\mathrm{h}}\right)$ of $\mathbf{4 4}^{\prime}$ DPEPO is estimated to be $1.20 \times 10^{-7}$ $\mathrm{cm}^{2} \mathrm{~V}^{-1} \mathrm{~s}^{-1}$, which is 10 fold that of $24^{\prime}$ DPEPO and 100 fold those of 22'DPEPO and 24DPEPO (Table 1). On account of the DPE-localized HOMOs for mDPEPO and the electrontransporting character of DPPO, the hole transporting abilities of $\boldsymbol{m D P E P O}$ should be in direct proportion to the exposure degree of their DPE as the main hole transporting channel. Although the superposition of the two DPPOs renders the deepest LUMO that of 24DPEPO, its electron mobility $\left(\mu_{\mathrm{e}}\right)$ is the lowest at $7.72 \times 10^{-9} \mathrm{~cm}^{2} \mathrm{~V}^{-1} \mathrm{~s}^{-1}$, which is only one tenth of that of $22^{\prime}$ DPEPO. In contrast, the $\mu_{\mathrm{e}}$ of $24^{\prime}$ DPEPO at $4.02 \times$ $10^{-6} \mathrm{~cm}^{2} \mathrm{~V}^{-1} \mathrm{~s}^{-1}$ is dramatically improved by 3 orders of magnitude, which is almost equivalent to that of $44^{\prime}$ DPEPO. According to the DFT results, both DPE and DPPO are involved in unoccupied molecular orbitals and incorporated into electron transportation (Fig. $\mathrm{S} 2 \dagger$ ). In this case, the various $\mu_{\mathrm{e}}$ of mDPEPO actually corresponds to their different intermolecular interplay. Compared to the over-concentration of DPPO with big steric hindrance in 24DPEPO and 22'DPEPO, by virtue of the relatively weaker steric effect of para-substituted DPPO and separation configurations, the intermolecular interplay of $\mathbf{2 4}^{\prime}$ DPEPO and $\mathbf{4 4}^{\prime}$ DPEPO is more effective to facilitate charge hopping between adjacent molecules. Furthermore, it is shown that the $J$ of $24^{\prime}$ DPEPO-based devices is intermediate between those of $22^{\prime}$ DPEPO and $\mathbf{4 4}^{\prime}$ DPEPO-based devices, revealing the carrier transporting ability of $\mathbf{2 4}^{\prime} \mathbf{D P E P O}$ as a combined result of steric and electronic coupling effects of its ortho- and parasubstituted DPPOs. Nevertheless, on the contrary to 24DPEPO with superposition configuration, the separation configuration of $\mathbf{2 4}^{\prime}$ DPEPO causes the superiority of its para-DPPO in electrical performance enhancement.

In general, through an asymmetrical separation configuration incorporating both ortho- and para-DPPO substitutions, 24'DPEPO successfully integrates the complementary advantages of $22^{\prime}$ DPEPO and $\mathbf{4 4}^{\prime}$ DPEPO in favorable optical characteristics and improved electrical performance, respectively, revealing its great potential in exciton harvesting and utilization.

\subsection{Device performance of deep-blue TADF diodes}

The well-controlled and differentiated optoelectronic properties of constitutional isomers mDPEPO establish the basis to selectively investigate the determinants of EL performance of blue TADF host materials. The devices were fabricated with a configuration of ITO $\left|\mathrm{MoO}_{3}(6 \mathrm{~nm})\right| \mathrm{NPB}(70 \mathrm{~nm})|m \mathrm{CP}(5 \mathrm{~nm})|$ mDPEPO:DMAC-DPS (20 nm, 10\% wt)|mDPEPO (5 nm)|Bphen $(30 \mathrm{~nm})|\mathrm{LiF}(1 \mathrm{~nm})| \mathrm{Al}$, in which $\mathrm{MoO}_{3}$ and LiF served as the hole and electron-injecting layer, NPB and Bphen are 4,4'-bis[ $N-(1-$ naphthyl)- $N$-phenylamino]biphenyl and 4,7-diphenyl-1,10-phenanthroline as hole and electron transporting layers and $m \mathrm{CP}\left(N, N^{\prime}\right.$-dicarbazole-3,5-benzene) and $\boldsymbol{m D P E P O}$ were used as exciton-blocking layers, respectively (Fig. 6a). The doping concentration was optimized as $10 \%$ wt (Fig. S $5 \dagger$ ). In contrast to the large energy barriers of $\sim 0.5 \mathrm{eV}$ between FMOs of $\boldsymbol{m D P E P O}$ and $m \mathrm{CP}$ and Bphen, the HOMO and LUMO energy levels of DMAC-DPS perfectly match with the corresponding FMO energy levels of $m \mathrm{CP}$ and Bphen, making the charge capture and exciton recombination on DMAC-DPS dominant in exciton harvesting. At high operation voltages, high-energy carriers can surmount the barriers to recombine on mDPEPO, making hostto-dopant energy transfer considerable. In this case, exciton quenching by host-host and host-dopant interactions can directly influence the device performance.

All of the devices showed deep blue emissions peaking at $460 \mathrm{~nm}$ at $1000 \mathrm{~cd} \mathrm{~m}^{-2}$ (inset in Fig. 6b). In comparison to the PL spectra, the hypochromatic shift of EL emissions should be attributed to the optical microcavity effect of nanometer-scaled devices. 22'DPEPO and 24'DPEPO-based devices achieved the highest color purity with Commission Internationale Ed I'eclairage (CIE) coordinates of $(0.16,0.17)$, owing to their rigid structures and LE-featured excited states (Table 2). In contrast, the relatively flexible structures and partially CT-type excited states of 24DPEPO and $\mathbf{4 4}^{\prime}$ DPEPO rendered broadened EL spectra with CIE coordinates of $(0.16,0.20)$ and $(0.16,0.18)$, respectively. The remarkably increased intensity of the longwavelength part in the EL emission from 24DPEPO-based devices was actually due to the decreased intensity of the shortwavelength part, which is readily quenched through nonradiative transitions during host-dopant interactions.

$I-V$ characteristics of these light-emitting devices showed a trend consistent with the charge mobility of their host materials (Fig. 6b). 44'DPEPO endowed its devices with the highest $J$, while the $J$ of $24^{\prime}$ DPEPO-based devices was secondary. Along with increasing operation voltage, the effect of $\mathbf{4 4}^{\prime}$ DPEPO and 24'DPEPO on enhancing $J$ became more prominent. However, the difference between the $J$ of these devices was remarkably smaller than that between the $J$ of the single-carrier transporting devices, especially at low driving voltages, which indicated the significant contribution of DMAC-DPS to carrier injection and transportation. Nevertheless, 44'DPEPO and 24'DPEPO endowed their devices with a maximum luminance of $\sim 6500 \mathrm{~cd} \mathrm{~m}^{-2}$, which was more than $2000 \mathrm{~cd} \mathrm{~m}^{-2}$ higher than that of $22^{\prime}$ DPEPO-based devices; meanwhile, when using 24DPEPO as a host, the maximum luminance was less than $1000 \mathrm{~cd} \mathrm{~m}^{-2}$. The higher luminance of $\mathbf{4 4}^{\prime}$ DPEPO and 24'DPEPO-based devices corresponded to higher exciton concentrations owing to larger and balanced charge flux in their EMLs. Furthermore, the driving voltages of $\mathbf{4 4}^{\prime}$ DPEPO-based devices were 3.6, 5.1 and $7.5 \mathrm{~V}$ for onset, 100 and $1000 \mathrm{~cd} \mathrm{~m}^{-2}$, respectively, which were lower than those of 22'DPEPO-based analogues (Table 2). 24'DPEPO further reduced the driving voltages of its devices to 3.5, 5.1 and $7.0 \mathrm{~V}$, which were about $1 \mathrm{~V}$ lower than those of 24DPEPO-based devices. In comparison to $\mathbf{4 4}^{\prime} \mathrm{DPEPO}$ with stronger electroactivity, the lower driving voltages achieved by $\mathbf{2 4}$ 'DPEPO actually reflected the higher exciton harvesting efficiency of its devices. ${ }^{25}$

On the basis of the four-layer device structure, $\mathbf{2 2}^{\prime}$ DPEPObased devices realized maximum efficiencies of $25.3 \mathrm{~cd} \mathrm{~A}^{-1}$ for current efficiency (CE), $21.5 \mathrm{~lm} \mathrm{~W}^{-1}$ for power efficiency (PE) and $16.7 \%$ for EQE, which were about $20 \%$ higher than those of $\mathbf{4 4}^{\prime}$ DPEPO-based devices (Fig. $6 \mathrm{c}$ and Table 2). The superiority of $\mathbf{2 2}^{\prime}$ DPEPO in the maximum efficiencies should be attributed to the effectively suppressed collision-induced quenching through 
a

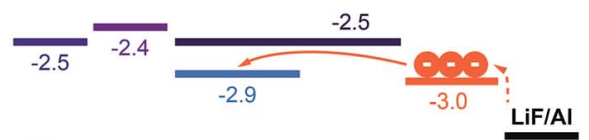

NPB $m C P$ DMAC-DPS xDPEPO BPhen

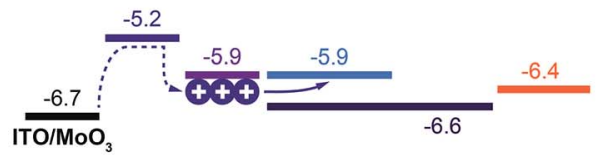

b

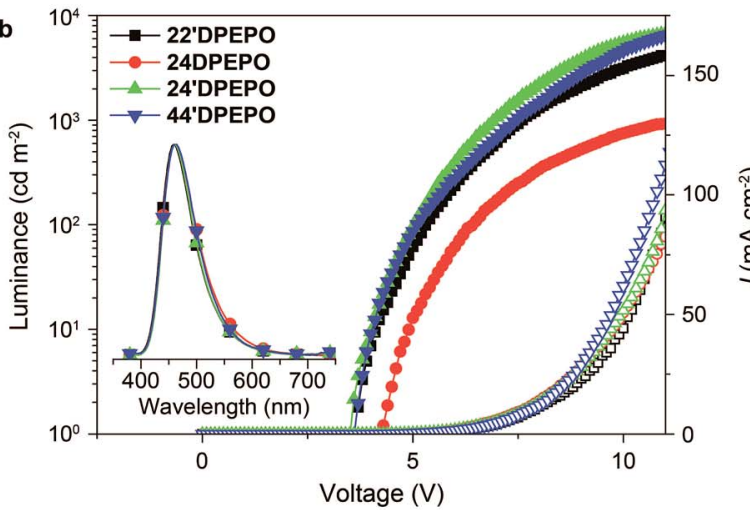

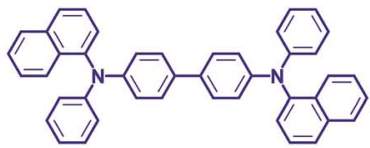

NPB
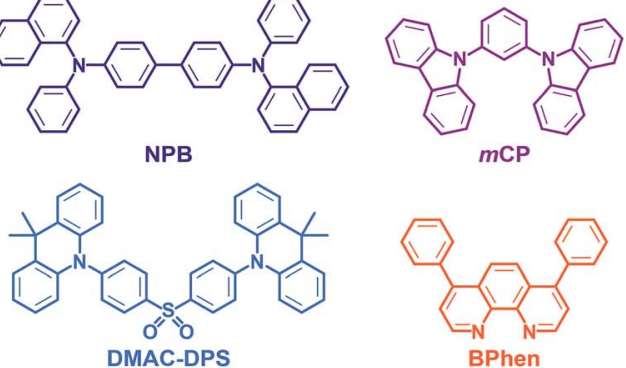

$m C P$
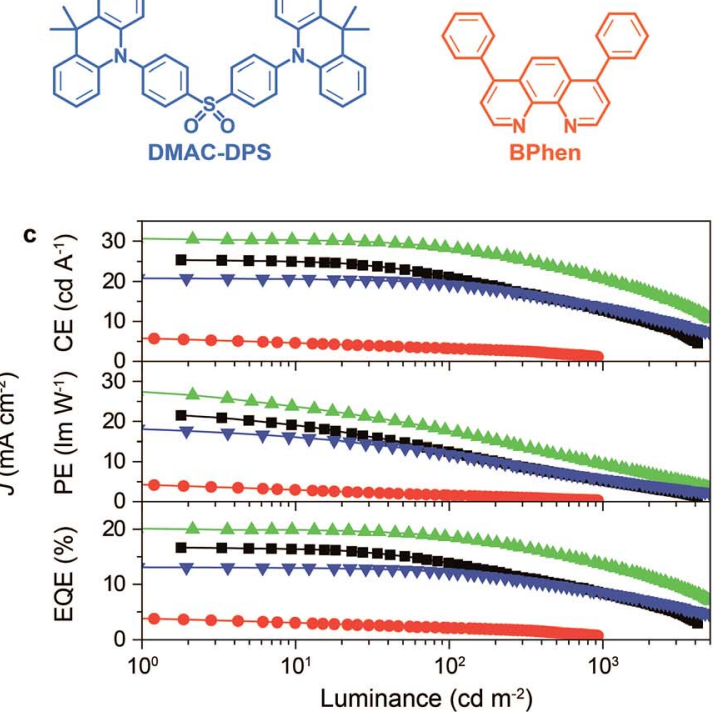

Fig. 6 (a) Device configuration and energy level diagram of mDPEPO-based deep blue TADF diodes and the chemical structures of employed materials; (b) luminance-J-voltage curves and EL spectra (inset) of DMAC-DPS-based devices using mDPEPO as hosts; (c) efficiency vs. luminance curves of the deep blue TADF devices.

reducing host-dopant interactions by virtue of the strong steric effect of its ortho-DPPOs. Significantly, in addition to the advantages of ortho-substituted DPPO, the unsymmetrical separation structure of $\mathbf{2 4}^{\prime}$ DPEPO further weakens intermolecular interactions, improving the maximum efficiencies to $30.6 \mathrm{~cd} \mathrm{~A} \mathrm{~A}^{-1}, 27.5 \mathrm{~lm} \mathrm{~W} \mathrm{~W}^{-1}$ and $20.1 \%$, which are among the best results for deep-blue TADF devices reported so far. ${ }^{4 a, 5 d, 5 e, 5 i, 5 j, 16 a}$ Therefore, compared to 22' DPEPO, the asymmetric configuration of $\mathbf{2 4}^{\prime} \mathbf{D P E P O}$ gives rise to the remarkable efficiency increase by $20 \%$. In contrast, the maximum efficiencies of 24DPEPObased devices were the lowest among these devices, suffering from serious exciton quenching through structural relaxationinduced nonradiative transitions.

Despite larger maximum efficiencies, 22'DPEPO-based devices showed serious efficiency reduction with roll-offs as large as 18 and $50 \%$ at 100 and $1000 \mathrm{~cd} \mathrm{~m}^{-2}$, respectively. With the best electrical performance among $m$ DPEPO, $44^{\prime}$ DPEPO facilitated charge flux balance in the EML of its devices, enhanced exciton recombination and reduced redundant charge concentration, thereby decreasing exciton-polaron collision probability for TPQ suppression. Consequently, on the contrary to $\mathbf{2 2}^{\prime}$ DPEPO, 44' DPEPO supported its devices with remarkably reduced roll-offs as low as 7 and $30 \%$ at 100 and $1000 \mathrm{~cd} \mathrm{~m}^{-2}$, respectively. Significantly, 24'DPEPO-based devices also realized low roll-offs of 8 and $32 \%$ at 100 and 1000 $\mathrm{cd} \mathrm{m}^{-2}$, respectively, comparable to those of 44'DPEPO-based analogues. The efficiency roll-offs of $24^{\prime}$ DPEPO and $\mathbf{4 4}^{\prime}$ DPEPObased devices are among the lowest values reported so far for deep-blue TADF diodes. ${ }^{4 a, 5 d, 5 e, 5 i, 5,16 a}$ If proportional to their charge mobility, TPQ suppression in these devices can be roughly evaluated in the order $4^{\prime}$ DPEPO $>\mathbf{2 4}^{\prime}$ DPEPO $>$ 22'DPEPO > 24DPEPO. On the other hand, compared to the

Table 2 EL performance of $m$ DPEPO-based devices employing DMAC-DPS as the TADF emitter

\begin{tabular}{|c|c|c|c|c|c|c|c|}
\hline \multirow[b]{2}{*}{ Host } & \multirow[b]{2}{*}{ Operation voltage $^{a}(\mathrm{~V})$} & \multirow[b]{2}{*}{ Maximum efficiency $^{b}$} & \multicolumn{3}{|c|}{ Efficiency roll-off $^{c}(\%)$} & \multirow[b]{2}{*}{ Emission peak (nm) } & \multirow[b]{2}{*}{$\operatorname{CIE}(x, y)$} \\
\hline & & & $\mathrm{CE}$ & $\mathrm{PE}$ & EQE & & \\
\hline 22'DPEPO & $3.7,5.4,7.6$ & $25.3,21.5,16.7$ & 18,50 & 44,75 & 19,50 & 460 & $0.16,0.17$ \\
\hline 24DPEPO & $4.3,6.5,-$ & $5.7,4.2,3.7$ & $44,-$ & $63,-$ & $44,-$ & 460 & $0.16,0.20$ \\
\hline 24' DPEPO & $3.5,5.1,7.0$ & $30.6,27.5,20.1$ & 8,33 & 37,66 & 8,32 & 460 & $0.16,0.17$ \\
\hline 44'DPEPO & $3.6,5.1,7.5$ & $20.8,18.1,13.1$ & 7,30 & 35,53 & 7,30 & 460 & $0.16,0.18$ \\
\hline
\end{tabular}

${ }^{a}$ Operating voltages for onset, 100 and $1000 \mathrm{~cd} \mathrm{~m}^{-2} \cdot{ }^{b}$ The maximum efficiencies of $\mathrm{CE}\left(\mathrm{cd} \mathrm{A}^{-1}\right), \mathrm{PE}\left(\mathrm{lm} \mathrm{W}^{-1}\right)$ and EQE $(\%) .{ }^{c}$ At 100 and $1000 \mathrm{~cd} \mathrm{~m}{ }^{-2}$. 
exposed $\mathrm{T}_{1}$ states of $22^{\prime}$ DPEPO and $44^{\prime}$ DPEPO, the extremely condensed $\mathrm{T}_{1}$ state of $2 \mathbf{4}^{\prime} \mathrm{DPEPO}$ can more effectively restrain collision-induced quenching, which offsets the slight inferiority of $24^{\prime}$ DPEPO to $\mathbf{4 4}^{\prime} \mathrm{DPEPO}$ in charge mobility. It would be rational that to some extent the enhanced efficiency stability at high luminance would reflect improved device durability, since device aging can be accelerated at high luminance to generate charge traps and exciton quenching sites, making both luminance and efficiency decrease. ${ }^{. e, 26}$ In this case, $\mathbf{2 4}^{\prime}$ DPEPO with reduced efficiency roll-off would be superior to $22^{\prime} \mathbf{D P E P O}$ in device stability.

The state-of-the-art performance of $24^{\prime}$ DPEPO-based devices clearly shows that for high-energy-gap blue TADF host materials, the strong steric effect is beneficial to suppress TTA for high efficiencies; while, under high driving voltages, the improved charge mobility can facilitate flux balance in EML to suppress TPQ. Significantly, with an effectively protected $\mathrm{T}_{1}$ state with an extremely condensed location, the EL performance of asymmetric $24^{\prime}$ DPEPO was far beyond simple integration of those of $\mathbf{2 2}^{\prime}$ DPEPO and $\mathbf{4 4}^{\prime}$ DPEPO, verifying the great importance of suppressing host-involved intermolecular interactions. The sky-blue devices of another TADF dye 1,2-bis(carbazol-9-yl)4,5-dicyanobenzene (2CzPN) employing $24^{\prime}$ DPEPO also showed higher efficiencies and reduced roll-off in contrast to $22^{\prime} \mathbf{D P E P O}$, displaying the universality of the host design strategy for 24'DPEPO (Fig. S6 †).

\section{Experimental section}

\subsection{Materials and instruments}

All the reagents and solvents used for the synthesis were purchased from Aldrich and Acros and used without further purification. DPEPO and DPESPO bromides were prepared according to our previous report. ${ }^{20 d}$

${ }^{1} \mathrm{H}$ NMR spectra were recorded using a Varian Mercury plus 400NB spectrometer relative to tetramethylsilane (TMS) as an internal standard. Molecular masses were determined using a FINNIGAN LCQ Electro-Spraying Ionization-Mass Spectrometer (ESI-MS), or a MALDI-TOF-MS. Elemental analyses were performed on a Vario EL III elemental analyzer. Absorption and photoluminescence (PL) emission spectra of the target compounds were measured using a SHIMADZU UV-3150 spectrophotometer and a SHIMADZU RF-5301PC spectrophotometer, respectively. Thermogravimetric analysis (TGA) and differential scanning calorimetry (DSC) were performed on Shimadzu DSC-60A and DTG-60A thermal analyzers under a nitrogen atmosphere at a heating rate of $10{ }^{\circ} \mathrm{C} \mathrm{min}^{-1}$. Cyclic voltammetric $(\mathrm{CV})$ studies were conducted using an Eco Chemie B. V. AUTOLAB potentiostat in a typical three-electrode cell with a platinum sheet working electrode, a platinum wire counter electrode, and a silver/silver nitrate $\left(\mathrm{Ag} / \mathrm{Ag}^{+}\right)$reference electrode. All electrochemical experiments were carried out under a nitrogen atmosphere at room temperature in dichloromethane. Phosphorescence spectra were measured in dichloromethane using an Edinburgh FPLS 920 fluorescence spectrophotometer at $77 \mathrm{~K}$ cooled by liquid nitrogen with a delay of $300 \mu \mathrm{s}$ using the Time-Correlated Single Photon
Counting (TCSPC) method with a microsecond pulsed xenon light source for $10 \mu \mathrm{s}$ to $10 \mathrm{~s}$ lifetime measurement, and a synchronization photomultiplier for signal collection and the Multi-Channel Scaling Mode of a PCS900 fast counter PC plugin card for data processing. The absolute PLQY of the films was measured with an integrating sphere.

General phosphorylation procedure for bromides. In $\mathrm{Ar}_{2}$, bromide (1 mmol), NaAc (1.1 mmol), $\mathrm{Pd}(\mathrm{Ac})_{2}(0.05 \mathrm{mmol})$ and $\mathrm{Ph}_{2} \mathrm{PH}(1.1 \mathrm{mmol})$ were dissolved in DMF $(10 \mathrm{~mL})$ and heated to reflux for $24 \mathrm{~h}$. After cooling to room temperature, water $(10 \mathrm{~mL})$ was added to the system, which was then extracted with $\mathrm{CH}_{2} \mathrm{Cl}_{2}$ $(3 \times 3 \mathrm{~mL})$. The organic layer was combined and dried with anhydrous sodium sulfate. The solvent was removed in vacuo to afford the crude phosphine intermediate product. Then, the phosphine was dissolved in $\mathrm{CH}_{2} \mathrm{Cl}_{2}(10 \mathrm{~mL}) . \mathrm{H}_{2} \mathrm{O}_{2}(30 \%, 4 \mathrm{~mL})$ was added to the solution dropwise and stirred for $2 \mathrm{~h}$ at $0{ }^{\circ} \mathrm{C}$. Then, the mixture was extracted using $\mathrm{CH}_{2} \mathrm{Cl}_{2}(3 \times 3 \mathrm{~mL})$. The organic layer was combined and dried with anhydrous sodium sulfate. The solvent was removed in vacuo, and then the residue was purified by flash column chromatography to afford the phosphine oxide product (Scheme 1).

2,4-Bis(diphenylphosphoryl)diphenylether (24DPEPO). 393 $\mathrm{mg}$ of white powder with a yield of $69 \%$. ${ }^{1} \mathrm{H}$ NMR (TMS, $\mathrm{CDCl}_{3}$, $400 \mathrm{MHz}): \delta=8.009-7.957(\mathrm{t}, J=10.4 \mathrm{~Hz}, 1 \mathrm{H}), 7.840-7.775(\mathrm{t}$, $J=12.8 \mathrm{~Hz}, 1 \mathrm{H}), 7.717-7.606(\mathrm{~m}, 8 \mathrm{H}), 7.566-7.284(\mathrm{~m}, 14 \mathrm{H})$, $6.862-6.821$ (q, $\left.J_{1}=4.4 \mathrm{~Hz}, J_{2}=8.4 \mathrm{~Hz}, J_{3}=1.2 \mathrm{~Hz}, 1 \mathrm{H}\right), 6.572-$ $6.550 \mathrm{ppm}(\mathrm{d}, J=10.0 \mathrm{~Hz}, 2 \mathrm{H})$; LDI-TOF: $m / z(\%): 570$ (100) $\left[\mathrm{M}^{+}\right]$; elemental analysis (\%) for $\mathrm{C}_{36} \mathrm{H}_{28} \mathrm{O}_{3} \mathrm{P}_{2}$ : C 75.78, $\mathrm{H}$ 4.95; found: $\mathrm{C}$ $75.82, \mathrm{H} 4.97$.

2,4'-Bis(diphenylphosphoryl)diphenylether (24'DPEPO). 439 $\mathrm{mg}$ of white powder with a yield of $77 \% .{ }^{1} \mathrm{H}$ NMR (TMS, $\mathrm{CDCl}_{3}$, $400 \mathrm{MHz}$ ): $\delta=8.062-8.007$ (q, $J_{1}=7.6 \mathrm{~Hz}, J_{2}=12.8 \mathrm{~Hz}, J_{3}=1.6$ $\mathrm{Hz}, 1 \mathrm{H}), 7.767-7.719\left(\mathrm{q}, J_{1}=6.8 \mathrm{~Hz}, J_{2}=12.4 \mathrm{~Hz}, J_{3}=1.6 \mathrm{~Hz}\right.$, $4 \mathrm{H}), 7.667-7.616$ (q, $\left.J_{1}=7.2 \mathrm{~Hz}, J_{2}=12.0 \mathrm{~Hz}, J_{3}=1.2 \mathrm{~Hz}, 4 \mathrm{H}\right)$, $7.589-7.534\left(\mathrm{q}, J_{1}=7.2 \mathrm{~Hz}, J_{2}=14.8 \mathrm{~Hz}, J_{3}=1.2 \mathrm{~Hz}, 3 \mathrm{H}\right), 7.506-$ $7.315(\mathrm{~m}, 3 \mathrm{H}), 6.930-6.897\left(\mathrm{q}, J_{1}=5.2 \mathrm{~Hz}, J_{2}=8.0 \mathrm{~Hz}, 1 \mathrm{H}\right)$, 6.665-6.638 ppm (dd, $\left.J_{1}=2.0 \mathrm{~Hz}, J_{2}=8.8 \mathrm{~Hz}, 2 \mathrm{H}\right)$; LDI-TOF: $\mathrm{m} / z$ (\%): 570 (100) $\left[\mathrm{M}^{+}\right]$; elemental analysis (\%) for $\mathrm{C}_{36} \mathrm{H}_{28} \mathrm{O}_{3} \mathrm{P}_{2}: \mathrm{C}$ 75.78, H 4.95; found: C 75.80, H 4.95.

4,4-Bis(diphenylphosphoryl)diphenylether (44'DPEPO). 428 $\mathrm{mg}$ of white powder with a yield of $75 \% .{ }^{1} \mathrm{H}$ NMR (TMS, $\mathrm{CDCl}_{3}$, $400 \mathrm{MHz}): \delta=7.691-7.621(\mathrm{~m}, 12 \mathrm{H}), 7.563-7.523\left(\mathrm{td}, J_{1}=1.2\right.$ $\left.\mathrm{Hz}, J_{2}=7.2 \mathrm{~Hz}, 4 \mathrm{H}\right), 7.482-7.438\left(\mathrm{td}, J_{1}=2.8 \mathrm{~Hz}, J_{2}=7.6 \mathrm{~Hz}\right.$, $8 \mathrm{H}$ ), 7.105-7.078 (dd, $J_{1}=2.4 \mathrm{~Hz}, J_{2}=8.8 \mathrm{~Hz}, 4 \mathrm{H}$ ); LDI-TOF: $m / z$ (\%): 570 (100) $\left[\mathrm{M}^{+}\right]$; elemental analysis (\%) for $\mathrm{C}_{36} \mathrm{H}_{28} \mathrm{O}_{3} \mathrm{P}_{2}: \mathrm{C}$ 75.78, H 4.95; found: C 75.77, H 4.94.

\subsection{Density functional theory (DFT) and time-dependent DFT (TDDFT) calculations}

DFT computations were carried out with different parameters for structure optimizations and vibration analyses. The ground states and triplet states of molecules in vacuum were optimized by the restricted and unrestricted formalism of Beck's threeparameter hybrid exchange functional ${ }^{27}$ and Lee, Yang and Parr's correlation functional ${ }^{28}$ (B3LYP)/6-31+G(d,p), respectively. The fully optimized stationary points were further 


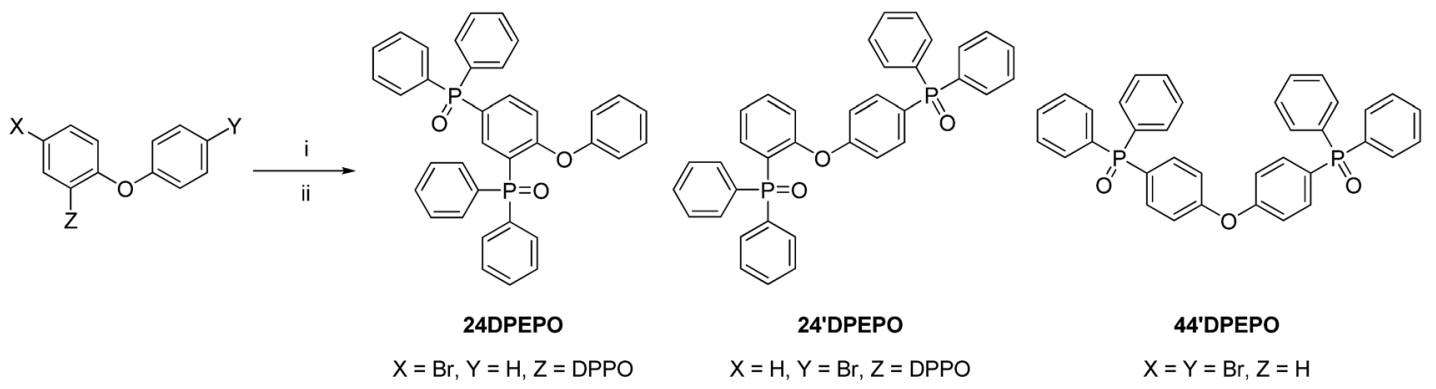

Scheme 1 Synthetic procedure of 24DPEPO, 24'DPEPO and 44'DPEPO. (i) $\mathrm{Ph}_{2} \mathrm{PH}, \mathrm{Pd}(\mathrm{Ac})_{2}, \mathrm{NaAc}, \mathrm{DMF}, 130{ }^{\circ} \mathrm{C}, 24 \mathrm{~h} ;(\mathrm{ii}) \mathrm{CH}_{2} \mathrm{Cl}_{2}, 30 \% \mathrm{H}_{2} \mathrm{O}_{2}, \mathrm{O}^{\circ} \mathrm{C}$.

characterized by harmonic vibrational frequency analysis to ensure that real local minima had been found without imaginary vibrational frequency. The total energies were also corrected by zero-point energy both for the ground state and triplet state. Natural transition orbital (NTO) analysis was performed on the basis of optimized ground-state geometries at the level of $(\mathrm{B} 3 \mathrm{LYP}) / 6-31+\mathrm{G}(\mathrm{d}, \mathrm{p}) .{ }^{23}$ The contours were visualized with Gaussview 5.0. All computations were performed using the Gaussian 09 package. $^{29}$

\subsection{Device fabrication and testing}

Before loading into a deposition chamber, the ITO substrate was cleaned with detergents and deionized water, dried in an oven at $120^{\circ} \mathrm{C}$ for $4 \mathrm{~h}$, and treated with oxygen plasma for $3 \mathrm{~min}$. Devices were fabricated by evaporating the organic layers at a rate of $0.1-0.2 \mathrm{~nm} \mathrm{~s}^{-1}$ onto the ITO substrate sequentially at a pressure below $4 \times 10^{-4} \mathrm{~Pa}$. Onto the electron-transporting layer, a layer of LiF with $1 \mathrm{~nm}$ thickness was deposited at a rate of $0.1 \mathrm{~nm} \mathrm{~s}^{-1}$ to improve electron injection. Finally, a $100 \mathrm{~nm}$ thick layer of $\mathrm{Al}$ was deposited at a rate of $0.6 \mathrm{~nm} \mathrm{~s}^{-1}$ as the cathode. The emission area of the devices was $0.09 \mathrm{~cm}^{2}$ as determined by the overlap area of the anode and the cathode. After fabrication, the devices were immediately transferred to a glove box for encapsulation with glass cover slips using epoxy glue. The EL spectra and CIE coordinates were measured using a PR650 spectra colorimeter. The current-density-voltage and brightness-voltage curves of the devices were measured using a Keithley 4200 source meter and a calibrated silicon photodiode. All the measurements were carried out at room temperature under ambient conditions. For each structure, five devices were fabricated to confirm the performance repeatability. To make conclusions reliable, the data reported herein were the closest to the average results.

\section{Conclusions}

A series of DPEPO-type host materials named $m$ DPEPO as constitutional isomers with two DPPO groups substituted on a DPE core at either the ortho- or para-position were designed and prepared. The steric effect of ortho-substituted DPPO and the electron coupling effect of para-substituted DPPO were successfully integrated through the separation configuration of 24'DPEPO, giving rise to its harmonious excited-state characteristics and electrical performance inherited from 22'DPEPO and 44'DPEPO, respectively. The asymmetrical configuration and the dominant orientation effect of orthosubstituted DPPO on the $\mathrm{T}_{1}$ location extremely condense the $\mathrm{T}_{1}$ state of $\mathbf{2 4}^{\prime}$ DPEPO onto a single phenyl, completely protected from intermolecular interactions. Consequently, 24'DPEPO endowed its DMAC-DPS-based deep blue TADF diodes with state-of-the-art performance featuring high EQE beyond 20\% and low roll-off at $32 \%$ at $1000 \mathrm{~cd} \mathrm{~m}^{-2}$, which was dramatically improved in comparison to those of $22^{\prime}$ DPEPO and $44^{\prime}$ DPEPO and successfully demonstrated its potential. This showed that besides common energy level optimization, more delicate and purposeful modulation on the optoelectronic properties of host materials is crucial for developing high-performance TADF diodes.

\section{Acknowledgements}

JZ and DD contributed equally to this work. HX thanks Prof. Runfeng Chen (Nanjing University of Posts and Telecommunication) for his assistance in the TDDFT simulation. This project was financially supported by NSFC (61176020 and 51373050), the New Century Excellent Talents Supporting Program of the Ministry of Education (China) (NCET-12-0706), the Program for Innovative Research Team in University (MOE) (IRT-1237), the Science and Technology Bureau of Heilongjiang Province (ZD201402 and JC2015002), the Education Bureau of Heilongjiang Province (2014CJHB005), the Fok Ying-Tong Education Foundation for Young Teachers in the Higher Education Institutions of China (141012) and Harbin Science and Technology Bureau (2015RAYXJ008).

\section{Notes and references}

1 D. M. de Leeuw, M. M. J. Simenon, A. R. Brown and R. E. F. Einerhand, Synth. Met., 1997, 87, 53.

2 (a) C. W. Tang and S. A. VanSlyke, Appl. Phys. Lett., 1987, 51, 913; (b) J. Kido, M. Kimura and K. Nagai, Science, 1995, 267, 1332; (c) M. A. Baldo, M. E. Thompson and S. R. Forrest, Nature, 2000, 403, 750; (d) C. D. Muller, A. Falcou, N. Reckefuss, M. Rojahn, V. Wiederhirn, P. Rudati, H. Frohne, O. Nuyken, H. Becker and K. Meerholz, Nature, 2003, 421, 829; (e) Y. R. Sun, N. C. Giebink, H. Kanno, B. W. Ma, M. E. Thompson and S. R. Forrest, Nature, 2006, 
440, 908; (f) S. Reineke, F. Lindner, G. Schwartz, N. Seidler, K. Walzer, B. Lussem and K. Leo, Nature, 2009, 459, 234; (g) F. B. Dias, K. N. Bourdakos, V. Jankus, K. C. Moss, K. T. Kamtekar, V. Bhalla, J. Santos, M. R. Bryce and A. P. Monkman, Adv. Mater., 2013, 25, 3707; (h) G. Schwartz, S. Reineke, T. C. Rosenow, K. Walzer and K. Leo, Adv. Funct. Mater., 2009, 19, 1319; (i) Q. Wang and D. Ma, Chem. Soc. Rev., 2010, 39, 2387.

3 (a) M. A. Baldo, D. F. O'Brien, Y. You, A. Shoustikov, S. Sibley, M. E. Thompson and S. R. Forrest, Nature, 1998, 395, 151; (b) H. Wu, L. Ying, W. Yang and Y. Cao, Chem. Soc. Rev., 2009, 38, 3391; (c) L. Xiao, Z. Chen, B. Qu, J. Luo, S. Kong, Q. Gong and J. Kido, Adv. Mater., 2011, 23, 926; (d) K. S. Yook and J. Y. Lee, Adv. Mater., 2012, 24, 3169; (e) Y. Tao, C. Yang and J. Qin, Chem. Soc. Rev., 2011, 40, 2943; (f) H. Xu, R. Chen, Q. Sun, W. Lai, Q. Su, W. Huang and X. Liu, Chem. Soc. Rev., 2014, 43, 3259; $(g)$ H. Xu, Q. Sun, Z. An, Y. Wei and X. Liu, Coord. Chem. Rev., 2015, 293-294, 228.

4 (a) H. Uoyama, K. Goushi, K. Shizu, H. Nomura and C. Adachi, Nature, 2012, 492, 234; (b) H. Nakanotani, T. Higuchi, T. Furukawa, K. Masui, K. Morimoto, M. Numata, H. Tanaka, Y. Sagara, T. Yasuda and C. Adachi, Nat. Commun., 2014, 5, 4016; (c) V. Jankus, P. Data, D. Graves, C. McGuinness, J. Santos, M. R. Bryce, F. B. Dias and A. P. Monkman, Adv. Funct. Mater., 2014, 24, 6178; (d) Y. Tao, K. Yuan, T. Chen, P. Xu, H. Li, R. Chen, C. Zheng, L. Zhang and W. Huang, Adv. Mater., 2014, 26, 7931.

5 (a) J.-Y. Hu, Y.-J. Pu, F. Satoh, S. Kawata, H. Katagiri, H. Sasabe and J. Kido, Adv. Funct. Mater., 2014, 24, 2064; (b) W. Li, D. Liu, F. Shen, D. Ma, Z. Wang, T. Feng, Y. Xu, B. Yang and Y. Ma, Adv. Funct. Mater., 2012, 22, 2797; (c) C. Mayr, S. Y. Lee, T. D. Schmidt, T. Yasuda, C. Adachi and W. Brütting, Adv. Funct. Mater., 2014, 24, 5232; (d) V. Jankus, C. J. Chiang, F. Dias and A. P. Monkman, Adv. Mater., 2013, 25, 1455; (e) M. Kim, S. K. Jeon, S.-H. Hwang and J. Y. Lee, Adv. Mater., 2015, 27, 2515; $(f)$ X.-L. Chen, R. Yu, Q.-K. Zhang, L.-J. Zhou, X.-Y. Wu, Q. Zhang and C.-Z. Lu, Chem. Mater., 2013, 25, 3910; $(g)$ T. Hofbeck, U. Monkowius and H. Yersin, J. Am. Chem. Soc., 2015, 137, 399; (h) M. J. Leitl, V. A. Krylova, P. I. Djurovich, M. E. Thompson and H. Yersin, J. Am. Chem. Soc., 2014, 136, 16032; (i) Q. Zhang, J. Li, K. Shizu, S. Huang, S. Hirata, H. Miyazaki and C. Adachi, J. Am. Chem. Soc., 2012, 134, 14706; (j) S. Hirata, Y. Sakai, K. Masui, H. Tanaka, S. Y. Lee, H. Nomura, N. Nakamura, M. Yasumatsu, H. Nakanotani, Q. Zhang, K. Shizu, H. Miyazaki and C. Adachi, Nat. Mater., 2015, 14, 330; (k) D. Zhang, L. Duan, D. Zhang, J. Qiao, G. Dong, L. Wang and Y. Qiu, Org. Electron., 2013, 14, 260; (l) H. Wang, L. Meng, X. Shen, X. Wei, X. Zheng, X. Lv, Y. Yi, Y. Wang and P. Wang, Adv. Mater., 2015, 27, 4041; $(\mathrm{m}) \mathrm{W}$. Y. Hung, G. C. Fang, Y. C. Chang, T. Y. Kuo, P. T. Chou, S. W. Lin and K. T. Wong, ACS Appl. Mater. Interfaces, 2013, 5, 6826; (n) X.-K. Liu, Z. Chen, C.-J. Zheng, C.-L. Liu, C.-S. Lee, F. Li, X.-M. Ou and X.-H. Zhang, Adv. Mater., 2015, 27, 2378; (o)
D. G. Cuttell, S.-M. Kuang, P. E. Fanwick, D. R. McMillin and R. A. Walton, J. Am. Chem. Soc., 2002, 124, 6.

6 (a) B. S. Kim and J. Y. Lee, ACS Appl. Mater. Interfaces, 2014, 6, 8396; (b) B. S. Kim and J. Y. Lee, Adv. Funct. Mater., 2014, 24, 3970-3977; (c) Y. J. Cho, K. S. Yook and J. Y. Lee, Adv. Mater., 2014, 26, 4050; (d) L.-S. Cui, Y.-M. Xie, Y.-K. Wang, C. Zhong, Y.-L. Deng, X.-Y. Liu, Z.-Q. Jiang and L.-S. Liao, Adv. Mater., 2015, 27, 4213; (e) D. Zhang, L. Duan, C. Li, Y. Li, H. Li, D. Zhang and Y. Qiu, Adv. Mater., 2014, 26, 5050.

7 Z. B. Wang, M. G. Helander, M. T. Greiner, J. Qiu and Z. H. Lu, J. Appl. Phys., 2010, 107, 034506.

8 G. Méhes, K. Goushi, W. J. Potscavage Jr and C. Adachi, Org. Electron., 2014, 15, 2027.

9 (a) S. Reineke, K. Walzer and K. Leo, Phys. Rev. B: Condens. Matter Mater. Phys., 2007, 75, 125328; (b) J. Kalinowski, W. Stampor, J. Mecedilzdotyk, M. Cocchi, D. Virgili, V. Fattori and P. Di Marco, Phys. Rev. B: Condens. Matter Mater. Phys., 2002, 66, 235321; (c) S. Reineke and M. A. Baldo, Phys. Status Solidi A, 2012, 209, 2341; (d) M. A. Baldo, C. Adachi and S. R. Forrest, Phys. Rev. B: Condens. Matter Mater. Phys., 2000, 62, 10967.

10 H. Zamani Siboni and H. Aziz, Org. Electron., 2013, 14, 2510. 11 S. K. Lower and M. A. El-Sayed, Chem. Rev., 1966, 66, 199. 12 D. Hertel and K. Meerholz, J. Phys. Chem. B, 2007, 111, 12075. 13 (a) B. Zhang, G. Tan, C.-S. Lam, B. Yao, C.-L. Ho, L. Liu, Z. Xie, W.-Y. Wong, J. Ding and L. Wang, Adv. Mater., 2012, 24, 1873; (b) C. Han, Z. Zhang, H. Xu, J. Li, G. Xie, R. Chen, Y. Zhao and W. Huang, Angew. Chem., Int. Ed., 2012, 51, 10104.

14 C. Han, L. Zhu, F. Zhao, Z. Zhang, J. Wang, Z. Deng, H. Xu, J. Li, D. Ma and P. Yan, Chem. Commun., 2014, 50, 2670.

15 W. Huang, B. Mi and Z. Gao, Organic Electronics, Science Press, Beijing, 2011.

16 (a) Q. Zhang, B. Li, S. Huang, H. Nomura, H. Tanaka and C. Adachi, Nat. Photonics, 2014, 8, 326; (b) D. R. Lee, M. Kim, S. K. Jeon, S.-H. Hwang, C. W. Lee and J. Y. Lee, Adv. Mater., 2015, 27, 5861; (c) M. Numata, T. Yasuda and C. Adachi, Chem. Commun., 2015, 51, 9443.

17 C. Han, Y. Zhao, H. Xu, J. Chen, Z. Deng, D. Ma, Q. Li and P. Yan, Chem.-Eur. J., 2011, 17, 5800.

18 W. Song, I. H. Lee, S.-H. Hwang and J. Y. Lee, Org. Electron., 2015, 23, 138.

19 W. Song, I. Lee and J. Y. Lee, Adv. Mater., 2015, 27, 43584363.

20 (a) C. Han, L. Zhu, J. Li, F. Zhao, Z. Zhang, H. Xu, Z. Deng, D. Ma and P. Yan, Adv. Mater., 2014, 26, 7070; (b) D. Yu, F. Zhao, C. Han, H. Xu, J. Li, Z. Zhang, Z. Deng, D. Ma and P. Yan, Adv. Mater., 2012, 24, 509; (c) Y. Tao, J. Xiao, C. Zheng, Z. Zhang, M. Yan, R. Chen, X. Zhou, H. Li, Z. An, Z. Wang, H. Xu and W. Huang, Angew. Chem., Int. Ed., 2013, 52, 10491; (d) C. Han, Z. Zhang, H. Xu, S. Yue, J. Li, P. Yan, Z. Deng, Y. Zhao, P. Yan and S. Liu, J. Am. Chem. Soc., 2012, 134, 19179.

21 (a) N. C. Giebink and S. R. Forrest, Phys. Rev. B: Condens. Matter Mater. Phys., 2008, 77, 235215; (b) D. Song, S. Zhao, Y. Luo and H. Aziz, Appl. Phys. Lett., 2010, 97, 243304. 
22 C. Han, L. Zhu, J. Li, F. Zhao, H. Xu, D. Ma and P. Yan, Chem.-Eur. J., 2014, 20, 16350.

23 R. L. Martin, J. Chem. Phys., 2003, 118, 4775.

24 (a) Z. An, C. Zheng, Y. Tao, R. Chen, H. Shi, T. Chen, Z. Wang, H. Li, R. Deng, X. Liu and W. Huang, Nat. Mater., 2015, 14, 685; (b) S. Hirata, K. Totani, J. Zhang, T. Yamashita, H. Kaji, S. R. Marder, T. Watanabe and C. Adachi, Adv. Funct. Mater., 2013, 23, 3386.

25 Z. Zhang, Z. Zhang, D. Ding, Y. Wei, H. Xu, J. Jia, Y. Zhao, K. Pan and W. Huang, J. Phys. Chem. C, 2014, 118, 20559.

26 Y. Noguchi, H.-J. Kim, R. Ishino, K. Goushi, C. Adachi, Y. Nakayama and H. Ishii, Org. Electron., 2015, 17, 184.

27 A. D. Becke, J. Chem. Phys., 1993, 98, 5648.

28 C. Lee, W. Yang and R. G. Parr, Phys. Rev. B: Condens. Matter Mater. Phys., 1988, 37, 785.

29 M. J. Frisch, G. W. Trucks, H. B. Schlegel, G. E. Scuseria, M. A. Robb, J. R. Cheeseman, G. Scalmani, V. Barone,
B. Mennucci, G. A. Petersson, H. Nakatsuji, M. Caricato, X. Li, H. P. Hratchian, A. F. Izmaylov, J. Bloino, G. Zheng, J. L. Sonnenberg, M. Hada, M. Ehara, K. Toyota, R. Fukuda, J. Hasegawa, M. Ishida, T. Nakajima, Y. Honda, O. Kitao, H. Nakai, T. Vreven, J. A. Montgomery Jr., J. E. Peralta, F. Ogliaro, M. Bearpark, J. J. Heyd, E. Brothers, K. N. Kudin, V. N. Staroverov, R. Kobayashi, J. Normand, K. Raghavachari, A. Rendell, J. C. Burant, S. S. Iyengar, J. Tomasi, M. Cossi, N. Rega, J. M. Millam, M. Klene, J. E. Knox, J. B. Cross, V. Bakken, C. Adamo, J. Jaramillo, R. Gomperts, R. E. Stratmann, O. Yazyev, A. J. Austin, R. Cammi, C. Pomelli, J. W. Ochterski, R. L. Martin, K. Morokuma, V. G. Zakrzewski, G. A. Voth, P. Salvador, J. J. Dannenberg, S. Dapprich, A. D. Daniels, Ö. Farkas, J. B. Foresman, J. V. Ortiz, J. Cioslowski and D. J. Fox, Gaussian 09, Revision D. 1, Gaussian, Inc., Wallingford CT, USA, 2009. 